\title{
Terpenes solubility in water and their environmental distribution
}

\author{
Mónia A.R. Martins ${ }^{\text {a }}$, Liliana P. Silva ${ }^{\text {a,b }}$, Olga Ferreira ${ }^{\text {b }}$, Bernd Schröder ${ }^{\text {a }}$, João A.P. Coutinho ${ }^{\text {a }}$, Simão P. Pinho ${ }^{\text {b,* }}$ \\ a CICECO - Aveiro Institute of Materials, Department of Chemistry, University of Aveiro, 3810-193 Aveiro, Portugal \\ ${ }^{\mathrm{b}}$ Associate Laboratory LSRE-LCM, Departamento de Tecnologia Química e Biológica, Instituto Politécnico de Bragança, 5300-253 Bragança, Portugal
}

\section{A R T I C L E I N F O}

\section{Article history:}

Received 21 April 2017

Received in revised form 19 June 2017

Accepted 21 June 2017

Available online 27 June 2017

\section{Keywords:}

Terpenes

Water

Solubility

Thermodynamic functions

Environmental distribution

\begin{abstract}
A B S T R A C T
Terpenes and terpenoids belong to the largest and most diverse class of natural products. Due to the increasing importance of their applications and the emerging perception of their impact on the environment, the available physico-chemical characterization is insufficient. In this work the water solubility of geraniol, linalool, DL-citronellol, thymol, eugenol, carvacrol and $p$-cymene, in the temperature range from (298.15 to 323.15$) \mathrm{K}$, and at atmospheric pressure, is studied. Due to the low solubility of these compounds a novel technique was adopted for their measurements and validated using the aqueous solubility data for sparingly soluble aromatic compounds. The thermodynamic properties of solution were derived from the experimental data at infinite dilution. It is shown that the solubility of terpenes in water is an endothermic process confirming the existence of UCST phase diagrams, and only for carvacrol and eugenol is entropically driven. The experimental information is shown in a two-dimensional chemical space diagram providing indications to their probable distribution in the environment once released.
\end{abstract}

(c) 2017 Elsevier B.V. All rights reserved.

\section{Introduction}

Terpenes, and their oxygenated derivatives, terpenoids, belong to what is probably the largest and most diverse class of natural compounds. They occur in all organisms, being the vast majority found in higher plants [1]. As components of essential oils, most of them are extensively used in different industrial sectors such as flavours, fragrances, spices, perfumeries, cosmetics, or food additives, and due to their biological activity, used for pharmaceutical and medical purposes [1-4].

In the pharmaceutical field, terpenes are used as excipients to enhance skin penetration, active principles of drugs, and components of non-prescription drugs [5]. In 2002, the sales on terpene-based pharmaceuticals were approximately US $\$ 12$ billion [5]. Examples are the antimalarial drug Artemisinin and the anticancer drug Taxol®, two of the better known terpene-based drugs [6-8]. Menthol and camphor are non-prescription drugs also widely used in the pharmaceutical field. In 2015, the sales of Salonpas (5.7\% menthol and $1.12 \%$ camphor) [9], a famous topical analgesic in the United States, reached \$60.1 million [10].

On a global scale, the extensive anthropogenic use of terpenes and terpenoids associated with their natural emissions from coniferous forests, are one of the principal sources of biogenic volatile organic compounds (BVOC) [11-13]. About half of global BVOC-emissions originate in isoprene, the terpenes building-block [14], and their role in aerosol formation became an important research topic on the

\footnotetext{
* Corresponding author.

E-mail address: spinho@ipb.pt (S.P. Pinho).
}

chemistry of the atmosphere, with a renewed emphasis due to the ongoing climate change debate $[12,15,16]$. Besides vapor pressure and octanol-water partition coefficients, aqueous solubility is an important parameter to allow an ample description of the distribution of a substance among the different environmental compartments.

With the increase of the importance of their commercial and industrial applications, process-relevant physico-chemical data of terpenes and terpenoids have been retrieved over time. Meanwhile, with the increasing number of terpenes applications allied to their impact on the environment, right through to implications on a global scale, those data are insufficient. Furthermore, the discovery of more compounds with novel structures, and interesting bioactivities, to the already classified 55,000 terpenes, enhances the need to establish new methods to efficiently measure the physicochemical properties of terpenes, contributing also for the development of predictive models based on molecular descriptors, quantum chemistry or equilibrium thermodynamics.

Aqueous solubility is therefore an essential property in fields such as pharmaceutical sciences, environmental studies or chemical engineering. Concerning terpenes only a few works focusing exclusively solidliquid equilibrium (SLE) or liquid-liquid equilibrium (LLE) of binary mixtures of terpenes and water have been published. In 1980, Smyrl and LeMaguer [17] investigated the solubilities of three terpenic essential oil components in water, with or without dissolved solids, at three temperatures. Later, Weidenhamer and co-workers [18] determined the solubility of 31 biologically active monoterpenes in water by chromatography. Miller and Hawthorne [19] presented solubilities of D-limonene, carvone, eugenol, 1,8-cineole, and nerol in subcritical water; while Fichan et al. [20] and Tamura and Li [21] investigated water 
solubilities of monoterpenes at $25^{\circ} \mathrm{C}$. By searching compilation books such as "Handbook of Aqueous Solubility Data" [22] it is possible to gauge the limited, and high inconsistency of the available data.

Among the vast range of terpenes, in this work seven showing similar structures and important properties or applications, were selected. Geraniol, linalool and DL-citronellol are non-cyclic monoterpenoids usually used as repellents [23]. Moreover, linalool is used as a scent in 60$80 \%$ of the perfumed cleaning agents and hygiene products, and as a synthetic precursor and chemical intermediate of vitamin D. DL-citronellol is also used as raw material for the synthesis of other terpenes [1,23]. Thymol, eugenol, carvacrol and $p$-cymene are monoterpenoids ( $p$ cymene is a monoterpene) that present an aromatic ring. $p$-Cymene occurs in the ethereal oils and is used to improve the odour of soaps, and as a solvent for dyes and varnishes. Carvacrol is a major component of oregano, and is applied as a disinfectant while eugenol is a component of clove and cinnamon oils, and both used in flavours and in dentistry. Finally, thymol occurs in the oil of thyme and oregano and it is applied as a topical antiseptic and antihelmintic [24]. This work reports their water solubility in the temperature range from (298.15 to 323.15 ) K using an experimental method recently adapted by us for sparingly soluble solid compounds, and here applied for the first time to study the solubility of liquids in water. The new technique was validated against data for some well-studied aromatic compounds and the data reported are compared with literature values. Additionally, a thermodynamic analysis through the thermodynamic properties of solution is explored, and the terpenes first distribution in the environment, predicted.

\section{Experimental}

\subsection{Chemicals}

The description of the chemicals used in this work is presented on Table 1. All compounds were stored at $278.15 \mathrm{~K}$ and used as received. However, the purity of each terpene was checked by ${ }^{1} \mathrm{H}$, and ${ }^{13} \mathrm{C}$ NMR spectra and GC-MS. The water used was double distilled, passed by a reverse osmosis system and further treated with a MilliQ plus 185 water purification apparatus (resistivity: $18.2 \mathrm{M} \Omega \mathrm{cm}$; TOC $<5 \mu \mathrm{g} \mathrm{dm}^{-3}$; free of particles $>0.22 \mu \mathrm{m}$ ). Toluene and $p$-xylene were used in order to validate the new application of the experimental method.

\subsection{Experimental procedure}

Due to the low solubility values of the compounds under study, an approach adapted from Andersson and Schräder (1999); Etzweiler et al. (1995); and Schräder and Andersson (2001) [25-27] was adopted here. The experimental setup was previously used by us [28] and proved to be efficient in the determination of aqueous solubilities of solid substances. In this work, toluene and $p$-xylene, which have a similar structure and solubility values of the same order of magnitude with the compounds under analysis, were used to validate the method for measuring solubilities of sparingly soluble liquid compounds in water.

The experimental setup used is displayed in Fig. S1 of Supporting information. The dialysis tubing cellulose membranes (D9277 from SIGMA) were previously humidified for at least $3 \mathrm{~h}$, and subjected to a pretreatment according to the instructions given by the manufacturer. Afterwards, the cellulose membranes of around $10 \mathrm{~cm}$ length were filled with ultra-pure water and placed in test tubes with solutions with an excess of terpene. One end of the dialysis tubing was closed with a tight knot and the other was fixed to a glass tube, which allows the sampling through a drilled rubber cup. The test tubes with the solutions were dispersed using an isothermal ultrasonic bath (Branson 250 \& 450 Sonifier) during one hour at $60 \%$, and then allowed to equilibrate in a thermostatized Julabo F38 - EH (V2) bath (accuracy $\pm 0.1 \mathrm{~K}$ ) under agitation (Thermo Scientific ${ }^{\mathrm{TM}}$ Cimarec $^{\mathrm{TM}}$ Micro Stirrers) for at least $24 \mathrm{~h}$. This period proved to be enough to guarantee the saturation. Samples of around $0.5-1 \mathrm{~g}$ were collected through the rubber cup from the inside of the dialysis membrane using plastic syringes, maintained at the same temperature of the analysis, and diluted in a binary solvent composed by $35 \%$ water and $65 \%$ methanol (mass percentage in solute free basis), which was also used to prepare the calibration curves. Solute concentration was obtained by UV-Vis spectroscopy, using a SHIMADZU UV-1700 PharmaSpec Spectrometer, at wavelengths indicated in Table 1 . These were found to be the maximum UV absorption wavelengths for the compounds studied. At least six independent measurements were carried out at each temperature. The main advantage of the present technique is that it avoids sampling solute not dissolved, but dispersed in the aqueous phase, a common experimental error, which often leads to overestimated solubility values.

Table 1

Name, structure, supplier, CAS, molar mass $(M)$, and purity (declared by the supplier) of the investigated compounds.

\begin{tabular}{|c|c|c|c|c|c|}
\hline Chemicals & Supplier & CAS & $\mathrm{M} / \mathrm{g} \cdot \mathrm{mol}^{-1}$ & Mass fraction purity & Wavelength/nm \\
\hline Geraniol & Sigma-Aldrich & $106-24-1$ & 154.25 & 0.98 & 242 \\
\hline Linalool & Aldrich & $78-70-6$ & 154.25 & 0.97 & 293 \\
\hline DL-Citronellol & Sigma & $106-22-9$ & 156.26 & $\approx 0.95$ & 238 \\
\hline Thymol & Sigma & $89-83-8$ & 150.22 & $\geq 0.995$ & 276 \\
\hline Eugenol & Aldrich & $97-53-0$ & 164.20 & 0.99 & 282 \\
\hline Carvacrol & SAFC & $499-75-2$ & 150.22 & 0.99 & 275 \\
\hline p-Cymene & Aldrich & $99-87-6$ & 134.22 & 0.99 & 274 \\
\hline Toluene & Sigma-Aldrich & $108-88-3$ & 92.14 & 0.998 & 262 \\
\hline p-Xylene & Acros organics & $1330-20-7$ & 106.16 & 0.99 & 275 \\
\hline Methanol & Fisher chemical & $67-56-1$ & 32.04 & 0.9999 & - \\
\hline
\end{tabular}




\section{Results and discussion}

\subsection{Method validation}

The experimental procedure used for the aqueous solubility determination was previously validated by us [28] for solid substances. In this work it is validated for liquid compounds using toluene and $p$-xylene, molecules with similar structure and solubilities values of the same order of magnitude of the substances under study. The procedure described above was followed, and the solubility in water of toluene and $p$-xylene determined at various temperatures. Results are presented in Table 2 and compared in Fig. 1 with values from the extensive and detailed study compilation by Góral et al. [29]. The results obtained by Neely et al. [30], published after that study were also included. As shown in Fig. 1, the results obtained demonstrate the reliability of the method for the measurement of the water solubility of sparingly soluble liquid substances.

\subsection{Aqueous solubilities}

Novel experimental aqueous solubility data for terpenes, along with the uncertainty for a 95\% confidence interval, are presented in Table 2 and Fig. S2 of SI. Despite the small solubility values, results are very satisfactory since the coefficient of variation defined as the ratio between the standard deviation to the average presents a maximum of $10.8 \%$ for linalool at $298.15 \mathrm{~K}$. Is important to mention that among the compounds investigated in this work, thymol is the only one that is solid at room temperature, with a melting point above $500 \mathrm{~K}$.

As shown in Table 2, with the exception of DL-citronellol the solubility of terpenes in water shows a monotonical increase with temperature. Moreover, mole fraction solubilities are in the order of $10^{-4}$, confirming the "hydrophobic" label usually attributed to this class of compounds and showing that the dissolved terpenes can be considered at infinite dilution. Concerning the compounds structures, at $298.15 \mathrm{~K}$, the terpene p-cymene, an alkylbenzene, presents the lowest solubilities while the terpenoid eugenol, a phenylpropene, presents the highest, what can be attributed to the presence of oxygenated groups. This is the expectable behavior given the increasing hydrophobic nature as we move from molecules with oxygenated groups to hydrocarbons. However, the temperature dependencies of the solubilities varies widely among the various compounds studied. From 298.15 to $323.15 \mathrm{~K}$ the solubility of geraniol increases around 12 times, while for DL-citronellol, eugenol and carvacrol only double their solubility, turning the measurements more difficult.

Carvacrol-thymol and geraniol-linalool are positional isomers and, as expected, their solubilities present similar values. However, while from 298.15 to $308.15 \mathrm{~K}$ carvacrol presents the highest solubility, at 313.15 and $318.15 \mathrm{~K}$ thymol is more soluble. Concerning the linear alcohols, linalool presents higher solubilities than the others up to $308.15 \mathrm{~K}$, above which geraniol is the most soluble.

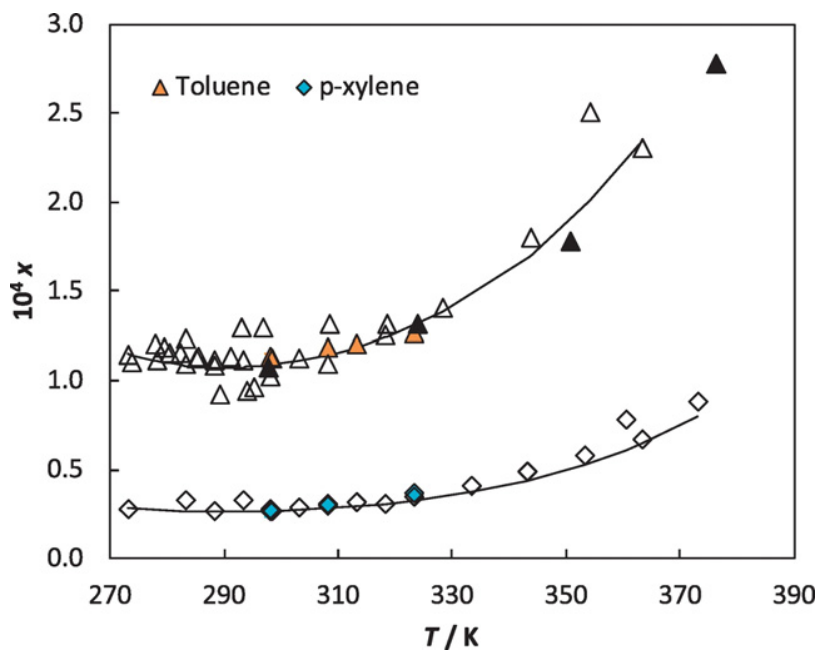

Fig. 1. Comparison of the experimental aqueous solubilities of toluene and $p$-xylene with data from literature. The colorful filled symbols represent experimental points measured in this work and the open symbols and lines represent experimental and calculated data compiled and selected by Góral et al. [29] The black filled triangles correspond to values measured by Neely et al. [30].

Among the non-cyclic terpenes studied, in general, DL-citronellol is the one presenting lower solubilities. This compound presents one double bond less when compared with linalool and geraniol, being more soluble at the lowest temperature only. In fact, it is relevant to mention the difficulty of measuring the solubility of DL-citronellol at low temperatures, due to the very small change in its solubility in that temperature range, and some enthalpic effects can be associated when comparing the solubility magnitudes of these three compounds. Regarding the aromatic terpenes group, $p$-cymene and eugenol present the lowest and highest solubilities in water, as stated before. Thymol and carvacrol present similar solubilities, between those of the other compounds.

The compounds $p$-cymene, $p$-xylene and toluene present very similar structures as can be seen in Fig. 2, and that was the reason why the last two were chosen to validate the experimental method here adopted. Like expected, the solubility decreases from toluene to $p$ cymene, with the increase of the number of $\mathrm{CH}_{2}$ groups.

One important objective of this work is to provide accurate experimental data of terpenes solubilities in water. However, like mentioned above, the number of terpenes known today is about 55,000. It is thus impracticable the study of all these molecules, and predictive models, or simple empirical correlations with some readily available parameters, would be of great help.

Computational methods as COSMO-RS [31], SPARC [32], UNIFAC [33] and EPI Suite [34], were tested in order to predict or estimate the solubility of the studied terpenes in water [35]. However, as can be seen in Table 3, none of them was able to predict satisfactorily the solubility values, nor even the solubility ranking among the different compounds

Table 2

Experimental mole fraction ( $\left.x_{\text {terpene }}\right)$ of terpenes in water as a function of temperature and at atmospheric pressure. ${ }^{\mathrm{a}}$

\begin{tabular}{|c|c|c|c|c|c|c|}
\hline & \multicolumn{6}{|l|}{$10^{4} x_{\text {terpene }}$} \\
\hline & $298.15 \mathrm{~K}$ & $303.15 \mathrm{~K}$ & $308.15 \mathrm{~K}$ & $313.15 \mathrm{~K}$ & $318.15 \mathrm{~K}$ & $323.15 \mathrm{~K}$ \\
\hline Geraniol & $1.027(0.330)$ & $1.390(0.066)$ & $3.747(0.366)$ & $6.429(0.099)$ & $9.222(0.315)$ & $12.652(0.087)$ \\
\hline Linalool & $1.808(1.756)$ & $3.320(0.406)$ & $4.723(0.236)$ & $5.920(0.424)$ & $8.438(0.849)$ & $11.080(1.306)$ \\
\hline DL-Citronellol & $2.177(0.114)$ & $1.874(0.391)$ & $1.866(0.327)$ & $2.082(0.028)$ & $2.487(0.068)$ & $3.084(0.044)$ \\
\hline Thymol & $1.180(0.060)$ & $1.327(0.047)$ & $1.457(0.069)$ & $1.689(0.150)$ & $1.890(0.050)$ & - \\
\hline Eugenol & $2.280(0.083)$ & $2.305(0.522)$ & $2.538(0.275)$ & $2.539(0.150)$ & $2.856(0.932)$ & $3.118(0.920)$ \\
\hline Carvacrol & $1.440(0.173)$ & $1.547(0.073)$ & $1.642(0.098)$ & $1.687(0.163)$ & $1.703(0.090)$ & $1.717(0.054)$ \\
\hline p-Cymene & $0.048(0.002)$ & $0.069(0.003)$ & $0.099(0.005)$ & $0.124(0.004)$ & $0.151(0.016)$ & $0.189(0.007)$ \\
\hline Toluene & $1.127(0.048)$ & - & $1.178(0.020)$ & $1.203(0.038)$ & - & $1.257(0.026)$ \\
\hline p-Xylene & $0.262(0.028)$ & - & $0.307(0.006)$ & - & - & $0.365(0.009)$ \\
\hline
\end{tabular}

\footnotetext{
a The expanded uncertainty for a $95 \%$ confidence interval is presented between brackets. The standard uncertainty of temperature is $u(T)=0.1 \mathrm{~K}$.
} 


\section{$1.127 \times 10^{-4}$}

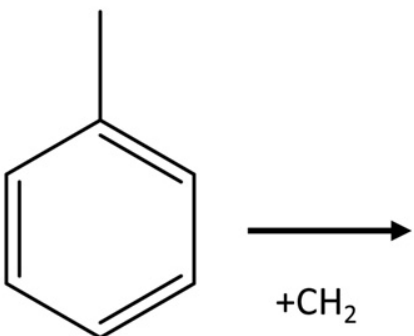

Toluene
$0.262 \times 10^{-4}$<smiles>Cc1ccc(C)cc1</smiles>

$p$-xylene
$0.048 \times 10^{-4}$

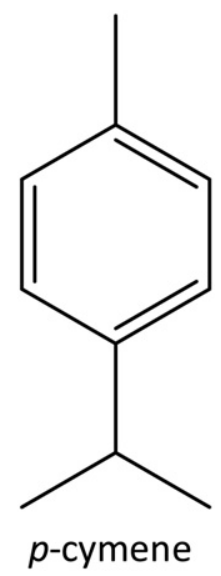

Fig. 2. Structures and mole fraction water solubilities of toluene, $p$-xylene and p-cymene at $298.15 \mathrm{~K}$.

studied. In particular, UNIFAC predicts a decrease on the solubility values when the temperature increases [35]. These methods are based on group or atom/fragment contributions, or need specific information to optimize the structure of the target compound, from which predictions can be made, and so it is not surprising the poor performances found as the methods were developed without much data on terpenes or terpenoids, since even currently there is almost none consistent or reliable information available. Therefore, the experimental data here presented are not only of enormous importance to assess modeling approaches, but more notably to include modifications in the description of these type of molecules, within models such as COSMO-RS, to improve the prediction capabilities concerning this vast family of compounds.

Several correlations of the solubility of terpenes in water with some of their properties, such as dipolar moment, octanol-water partition coefficient, solubility parameter or molar volume at several temperatures were attempted. However, no interesting results were achieved.

\subsection{Comparison with literature}

Literature values on terpenes water solubilities were previously reported and are listed in Table S1 and Fig. S3 of SI, along with the experimental values from this work. Only experimental data at atmospheric pressure were selected (data points predicted or estimated were omitted). Up to date, and to the best of our knowledge, only the values displayed in Table S1 were reported. For each terpene only a few reliable literature data are available, which poorly or roughly illustrates the behavior with temperature and makes the comparison with literature extremely difficult.

With a few exceptions, linalool and thymol, for which more literature information is available, show satisfactory agreement with the data measured in this work. Carvacrol presents a maximum relative

Table 3

Experimental and calculated mole fraction ( $x_{\text {terpene }}$ ) of terpenes in water at $298.15 \mathrm{~K}$.

\begin{tabular}{lllll}
\hline $10^{4} x_{\text {terpene }}$ & This work & COSMO-RS [31] & SPARC [32] & EPI Suite [34] \\
\hline Geraniol & 1.027 & 0.727 & 0.140 & 0.300 \\
Linalool & 1.808 & 0.615 & 0.344 & 0.801 \\
DL-Citronellol & 2.177 & 0.653 & 0.222 & 0.122 \\
Thymol & 1.180 & 0.284 & 1.370 & 0.526 \\
Eugenol & 2.280 & 0.235 & 0.267 & 0.830 \\
Carvacrol & 1.440 & 2.501 & 2.027 & 0.362 \\
$p$-Cymene & 0.048 & 0.031 & 0.027 & 0.038
\end{tabular}

deviation $\left(\mathrm{RD} / \%=\left|x_{\exp }-x_{\text {lit }}\right| x_{\text {lit }}^{-1}\right)$ of $20 \%$ at $298.15 \mathrm{~K}$. Data for DL-citronellol reported in the overlapping temperatures to our measurements, deviate $>100 \%$; with the exception of the value measured by Knobloch et al. [36] which present RD of about 35\%. RD for eugenol range between 16 and $>100 \%$, and for p-cymene range between 32 and 90\%, revealing also the high inconsistency among data already reported by different researchers. The same can be seen in geraniol, where at $298.15 \mathrm{~K}$ the RD varies between 3 and $25 \%$, and at $313.15 \mathrm{~K}$ is $>100 \%$.

The large discrepancies between literature data and the experimental values here reported, and between the literature values themselves can be assigned to different experimental conditions and techniques used, and to the fact that most of the literature values are rather old. In general, taking into account the nature of the compounds here investigated, errors may be attributed to deficient saturation and sampling techniques. Thus, in this work a special procedure was applied where the use of an isothermal ultrasonic bath to speed up the dispersion guarantee the saturation; a binary solvent of water and methanol used in dilutions and calibration curves avoid dissolution problems what is very important given the hydrophobicity of these compounds; and the use of dialysis membranes avoid sampling of non-dissolved solute, which lead to overestimated solubility values, usually found by us before its use. In fact, the validation methodology implemented by studying the solubility of toluene and $p$-xylene, also support the data presented in this work.

\subsection{Thermodynamic functions}

In order to describe the experimental solubility of terpenes in water and taking into account the significant dependence on temperature for the enthalpy of solution, several correlations were attempted as those proposed by Tsonopoulos [37], Góral [29] and Maczynski et al. [38]. However, the most suitable was found to be a linear equation that considers the harmonic temperature $[39,40]$ :

$$
\ln x_{\text {terpene }}=A+B\left(\frac{1}{T}-\frac{1}{T_{h m}}\right)
$$

where $T$ and $T_{h m}$ are the absolute and harmonic temperatures, respectively; and $A$ and $B$ are the fitted parameters.

Table 4 presents the fitted parameters along with the corresponding errors considering a confidence level of 95\%; where the absolute average relative deviation in the experimental mole fraction data is of $5.4 \%$.

Through the temperature dependence of the experimental solubility data and assuming infinite dilution of the solubility in water, it is possible to derive the standard molar thermodynamic functions of solution: 
Table 4

Estimated parameters for the mole fraction of terpenes in water estimated using Eq. (1), along with the corresponding errors at the 95\% confidence level.

\begin{tabular}{lll}
\hline & $A$ & $B / \mathrm{K}^{-1}$ \\
\hline Geraniol & $-7.8 \pm 0.23$ & $-10,361 \pm 2555$ \\
Linalool & $-7.6 \pm 0.12$ & $-6675 \pm 1313$ \\
DL-Citronellol & $-8.4 \pm 0.16$ & $-1456 \pm 1859$ \\
Thymol & $-8.8 \pm 0.05$ & $-1932 \pm 547$ \\
Eugenol & $-8.3 \pm 0.04$ & $-1210 \pm 479$ \\
Carvacrol & $-8.7 \pm 0.03$ & $-663 \pm 346$ \\
p-Cymene & $-11.5 \pm 0.08$ & $-5217 \pm 859$ \\
Toluene & $-9.0 \pm 0.01$ & $-420 \pm 37$ \\
\hline & &
\end{tabular}

Gibbs energy $\left(\Delta_{\text {sol }} G_{m}^{0}\right)$, enthalpy $\left(\Delta_{\text {sol }} H_{m}^{0}\right)$ and entropy $\left(\Delta_{\text {sol }} S_{m}^{0}\right)$, using eqs. $2-4$. Results are presented in Table 5.

$\Delta_{s o l} G_{m}^{0}=-R T \ln (x)_{p}$

$\frac{\Delta_{\text {sol }} H_{m}^{0}}{R T^{2}}=\left(\frac{\partial \ln x}{\partial T}\right)_{p}$

$\Delta_{s o l} S_{m}^{0}=R\left[\frac{\partial(T \ln x)}{\partial T}\right]_{p}$

where $R$ is the ideal gas constant and subscripts $p$ and $m$ indicates isobaric condition and constant composition during the process, respectively.

The molar thermodynamic properties of solution reported in Table 5 help to explore molecular mechanisms behind the solvation phenomena. The positive enthalpies of solution show that the dissolution of terpenes in water is an endothermic process and confirm the existence of UCST phase diagrams assumed before. Very evidently, geraniol and linalool present a very unfavorable enthalpic term when compared with all the other terpenes, while an enthalpic-entropic compensation phenomena occurs as eugenol and carvacrol show a very unfavorable entropic effect while their solution enthalpy are much smaller. Moreover, the standard Gibbs energy of solution increases with the reduction of functional groups present in the molecules. Eugenol presents the lowest standard Gibbs energy of solution, $p$-xylene the highest, while the isomers carvacrol and thymol present similar values. With only four experimental points the same procedure was applied to toluene solubility. The standard enthalpy of solution is $3.5 \mathrm{~kJ} / \mathrm{mol}$ at the harmonic temperature $310.4 \mathrm{~K}$, which is comparable to $4.36 \mathrm{~kJ} / \mathrm{mol}$ measured by a flow micro-calorimetric method at $308.2 \mathrm{~K}$ [41], and to $4.56 \mathrm{~kJ} / \mathrm{mol}$ found using the solubility data by Neely et al. [30], supporting also the good quality of the experimental data collected in this work, as in the compilation analysis by Hefter [42] the enthalpy of solution at $298.15 \mathrm{~K}$, calculated from different aqueous solubility sets, are in the range between 1.5 and $4.7 \mathrm{~kJ} / \mathrm{mol}$.

Table 5

0.09 pt? $>$ Standard thermodynamic molar properties of solution of terpenes in water at $T_{h m}=310.42 \mathrm{~K}$ together with the errors at the $95 \%$ confidence level.

\begin{tabular}{llll}
\hline & $\Delta_{\text {sol }} H_{m}^{0} / \mathrm{kJ} \cdot \mathrm{mol}^{-1}$ & $\Delta_{\text {sol }} G_{m}^{0} / \mathrm{kJ} \cdot \mathrm{mol}^{-1}$ & $T_{h m} \Delta_{\text {sol }} S_{m}^{0} / \mathrm{kJ} \cdot \mathrm{mol}^{-1}$ \\
\hline Geraniol & $86.2 \pm 21.2$ & $23.7 \pm 0.8$ & $62.5 \pm 21.3$ \\
Linalool & $55.5 \pm 10.9$ & $22.2 \pm 2.5$ & $33.3 \pm 11.2$ \\
DL-Citronellol & $12.1 \pm 15.5$ & $21.8 \pm 0.1$ & $-9.7 \pm 15.5$ \\
Thymol & $16.1 \pm 4.6$ & $23.3 \pm 0.1$ & $-7.3 \pm 4.6$ \\
Eugenol & $10.1 \pm 4.0$ & $21.6 \pm 0.1$ & $-11.6 \pm 4.0$ \\
Carvacrol & $5.5 \pm 2.9$ & $22.8 \pm 0.3$ & $-17.3 \pm 2.9$ \\
p-Cymene & $43.4 \pm 7.2$ & $31.6 \pm 0.1$ & $11.7 \pm 7.2$ \\
Toluene & $3.5 \pm 0.3$ & $23.5 \pm 0.1$ & $-20.0 \pm 0.3$
\end{tabular}

\subsection{Environmental distribution}

The environment is modelled as volumes of air, water, and octanol, where octanol represents the organic fraction appearing in soils and sediments. Thus, Gouin et al. [43] proposed a qualitative approach that allows to have a first screen of compounds with respect to their probable distribution in the environment once released. This was used by us before [28] and is here applied to terpenes and terpenoids. Here, octanol-water $\left(\log K_{\mathrm{OW}}\right)$ and air-water $\left(\log K_{\mathrm{AW}}\right)$ partition coefficients are introduced in a two-dimensional plot describing a hypothetical chemical space as represented in Fig. 3. Additional details about this approach are given in supporting information (SM1).

The air-water partition coefficients are most intimately related to aqueous solubility and vapor pressure. The experimental aqueous solubility data from this work were used to calculate the $\log K_{\mathrm{Aw}}$, together with vapor pressures collected from literature [44-50]. Octanol-water partition coefficients were measured experimentally by Griffin et al. [51]. Isoprene data, used here as a references, were taken from Mackay et al. [50].

The lines in Fig. 3 (1\% and 99\%) divide the chemical space into different regions in which partitioning is occurring almost exclusively into one medium. In general, terpenes are partitioning into the three environmental compartments while toluene, $p$-xylene and isoprene partition exclusively into air due to their high vapor pressure. DL-citronellol is the only compound that only distributes between water and octanol phases. Its rather high value of $\log K_{\mathrm{OH}}$ makes it to be more persistent in the environment. Due to its high solubility in water, eugenol will partially be found in the water phase. $p$-cymene partition mostly between air and octanol.

\section{Conclusions}

The solubility of seven terpenes in water at six different temperatures was evaluated using a new experimental methodology. The new experimental method was successfully validated for liquid substances using toluene and $p$-xylene as model compounds, proving to give reliable and precise experimental data. The thermodynamic properties of solution were calculated indicate that the solubility of terpenes in water is an endothermic process, confirming the existence of UCST

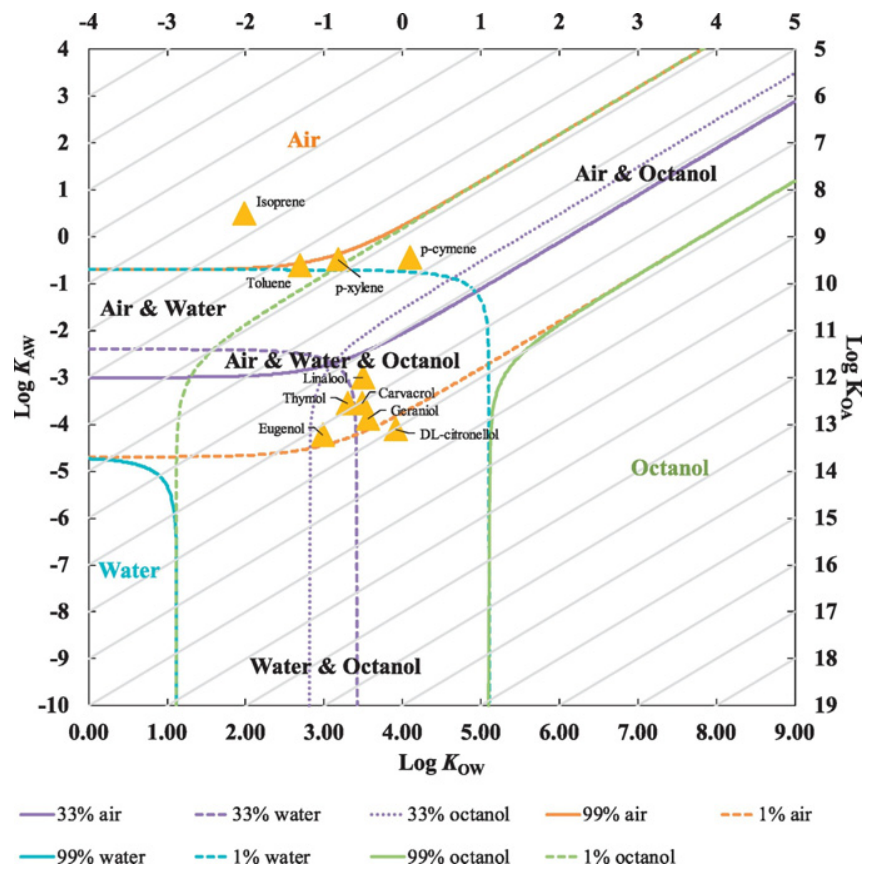

Fig. 3. Chemical space diagram of the terpenes investigated in this work and some other selected compounds, namely isoprene, toluene and $p$-xylene. 
phase diagrams and, excepting carvacrol and eugenol, enthalpically driven. A two-dimensional chemical space diagram shows that, in general, terpenes partition into the three environmental compartments, while toluene and $p$-xylene partition exclusively into air due to their higher vapor pressure.

This work contributes and calls for increasing the availability of reliable experimental physico-chemical property data of terpenes, which are also of enormous importance to the improvement, development and test new computational methods aiming for their prediction in such a vast family of compounds. Efforts must be focused in measuring or re-measuring basic important properties as mutual solubilities, vapor pressures, and octanol-water partition coefficients, where available, are very often of dubious quality.

\section{Acknowledgements}

This work was developed in the scope of the project CICECO - Aveiro Institute of Materials, POCI-01-0145-FEDER-007679, and Associate Laboratory LSRE-LCM, POCI-01-0145-FEDER-006984, both funded by FEDER under the PT2020 Partnership Agreement - Programa Operacional Competitividade e Internacionalização (POCI) - and by national funds through FCT - Fundação para a Ciência e a Tecnologia. M.A.R.M acknowledges FCT for her PhD grant (SFRH/BD/87084/2012).

\section{Appendix A. Supplementary data}

Supplementary data to this article can be found online at http://dx. doi.org/10.1016/j.molliq.2017.06.099.

\section{References}

[1] W. Schwab, C. Fuchs, F.-C. Huang, Transformation of terpenes into fine chemicals, Eur. J. Lipid Sci. Technol. 115 (2013) 3-8, http://dx.doi.org/10.1002/ejlt.201200157.

[2] S. Zwenger, C. Basu, Plant terpenoids: applications and future potentials, Biotechnol. Mol. Biol. Rev. 3 (2008) 1-7, http://dx.doi.org/10.5897/BMBR.

[3] L. Caputi, E. Aprea, Use of terpenoids as natural flavouring compounds in food industry, Recent Pat. Food Nutr. Agric. 3 (2011) 9-16, http://dx.doi.org/10.2174 2212798411103010009.

[4] J. Bohlmann, C.I. Keeling, Terpenoid biomaterials, Plant J. 54 (2008) 656-669, http:// dx.doi.org/10.1111/j.1365-313X.2008.03449.x.

[5] A.G. Guimarães, M.R. Serafini, L.J. Quintans-Júnior, Terpenes and derivatives as a new perspective for pain treatment: a patent review, Expert Opin. Ther. Pat. 24 (2014) 243-265, http://dx.doi.org/10.1517/13543776.2014.870154.

[6] D.J. Newman, G.M. Cragg, Natural products as sources of new drugs over the 30 years from 1981 to 2010, J. Nat. Prod. 75 (2012) 311-335, http://dx.doi.org/10. 1021/np200906s.

[7] M.S. Butler, Natural products to drugs: natural product-derived compounds in clinical trials, Nat. Prod. Rep. 25 (2008) 475-516, http://dx doi.org/10.1039/b514294f.

[8] L. Zhang, A.L. Demain, Natural Products - Drug Discovery and Therapeutic Medicine, 1st ed. Humana Press, New Delhi, India, 2005.

[9] C.L. Feucht, Analgesics and anti-inflammatory medications in sports: use and abuse Pediatr. Clin. N. Am. 57 (2010) 751-774, http://dx.doi.org/10.1016/j.pcl.2010.02.004

[10] R. Monks, Natural Ingredients, Rapid Relief top of Mind, DSN Drug Store News, http://dig.drugstorenews.com/2015-09-21-dsn/ 2015 (accessed August 24, 2016).

[11] I.H. Rogers, Environmental effects of terpenoid chemicals: a review, J. Am. Oil Chem Soc. 55 (1978) A113-A118, http://dx.doi.org/10.1007/BF02676926.

[12] J. Kesselmeier, M. Staudt, Biogenic volatile organic compounds (VOC): an overview on emission, physiology and ecology, J. Atmos. Chem. 33 (1999) 23-88, http://dx. doi.org/10.1023/A:1006127516791.

[13] T.M. Svendby, M. Lazaridis, K. Tørseth, Temperature dependent secondary organic aerosol formation from terpenes and aromatics, J. Atmos. Chem. 59 (2008) 25-46 http://dx.doi.org/10.1007/s10874-007-9093-7.

[14] C. Wiedinmeyer, A. Guenther, P. Harley, N. Hewitt, C. Geron, P. Artaxo, R. Steinbrecher, R. Rasmussen, Global organic emissions from vegetation, in: C. Garnier, P. Artaxo, C. Reeves (Eds.), Emission of Atmospheric Trace Compounds, Kluwer Academic Publishers, Dordrecht, Netherlands 2004, pp. 115-170.

[15] A. Guenther, C.N. Hewitt, D. Erickson, R. Fall, C. Geron, T. Graedel, P. Harley, L. Klinger, M. Lerdau, W.A. McKay, T. Pierce, B. Scholes, R. Steinbrecher, R. Tallamraju, J. Taylor, P. Zimmerman, A global model of natural volatile organic compound emissions, J. Geophys. Res. Atmos. 100 (1995) 8873-8892, http://dx.doi.org/ 10.1029/94JD02950.

[16] R. Steinbrecher, R. Koppmann, Biosphäre und Atmosphäre: Bedeutung biogener Kohlenwasserstoffe, Chemie Unserer Zeit. 41 (2007) 286-292, http://dx.doi.org/ 10.1002/ciuz.200700422.
[17] T.G. Smyrl, M. LeMaguer, Solubilities of terpenic essential oil components in aqueous solutions, J. Chem. Eng. Data 25 (1980) 150-152, http://dx.doi.org/10.1021/ je60085a005.

[18] J. Weidenhamer, F. Macias, N. Fischer, G.B. Williamson, Just how insoluble are monoterpenes? J. Chem. Ecol. 19 (1993) 1799-1807, http://dx.doi.org/10.1007/ BF00982309.

[19] D.J. Miller, S.B. Hawthorne, Solubility of liquid organic flavor and fragrance compounds in subcritical (hot/liquid) water from $298 \mathrm{~K}$ to $473 \mathrm{~K}$, J. Chem. Eng. Data 45 (2000) 315-318, http://dx.doi.org/10.1021/je990278a.

[20] I. Fichan, C. Larroche, J.B. Gros, Water solubility, vapor pressure, and activity coefficients of terpenes and terpenoids, J. Chem. Eng. Data 44 (1998) 56-62, http://dx. doi.org/10.1021/je980070+.

[21] K. Tamura, H. Li, Mutual solubilities of terpene in methanol and water and their multicomponent liquid-liquid equilibria, J. Chem. Eng. Data 50 (2005) 2013-2018, http://dx.doi.org/10.1021/je0502391.

[22] S.H. Yalkowsky, Y. He, P. Jain, Handbook of Aqueous Solubility Data, 2nd ed. CRC Press, 2010.

[23] C. Sell, A Fragrant Introduction to Terpenoid Chemistry, The Royal Society of Chemistry, Cambridge, UK, 2003.

[24] H. Surburg, J. Panten, Common Fragrance and Flavor Materials: Preparation, Properties and Uses, 5th ed. Wiley-VCH, 2006 http://www.wiley.com/WileyCDA/ WileyTitle/productCd-352731315X.html (accessed May 16, 2016).

[25] J.T. Andersson, W. Schräder, A method for measuring 1-octanol - water partition coefficients, Anal. Chem. 71 (1999) 3610-3614, http://dx.doi.org/10.1021/ac9902291.

[26] F. Etzweiler, E. Senn, H.W.H. Schmidt, Method for measuring aqueous solubilities of organic compounds, Anal. Chem. 67 (1995) 655-658, http://dx.doi.org/10.1021/ ac00099a025.

[27] W. Schräder, J.T. Andersson, Fast and direct method for measuring 1-octanol-water partition coefficients exemplified for six local anesthetics, J. Pharm. Sci. 90 (2001) 1948-1954, http://dx.doi.org/10.1002/jps.1145.

[28] B. Schröder, M.A.R.R. Martins, J.A.P.P. Coutinho, S.P. Pinho, Aqueous solubilities of five $\mathrm{N}$-(diethylaminothiocarbonyl)benzimido derivatives at $\mathrm{T}=298.15 \mathrm{~K}$, Chemosphere 160 (2016) 45-53, http://dx.doi.org/10.1016/j.chemosphere.2016.06.042.

[29] M. Góral, Recommended liquid-liquid equilibrium data. Part 3. Alkylbenzene-water systems, J. Phys. Chem. Ref. Data 33 (2004) 1159-1188, http://dx.doi.org/10.1063/1. 1797038 .

[30] B.J. Neely, J. Wagner, R.L. Robinson, K.A.M. Gasem, Mutual solubility measurements of hydrocarbon-water systems containing benzene, toluene, and 3-methylpentane, J. Chem. Eng. Data 53 (2008) 165-174, http://dx.doi.org/10.1021/je700449z.

[31] A. Klamt, COSMO-RS From Quantum Chemistry to Fluid Phase Thermodynamics and Drug Design, Elsevier, Amsterdam, The Netherlands, 2005.

[32] SPARC on-line calculator, October 2011 release w4.6.1691-s4.6.1687. (Accessed May 2013).

[33] J. Gmehling, J. Li, M. Schiller, A modified UNIFAC model. 2. Present parameter matrix and results for different thermodynamic properties, Ind. Eng. Chem. Res. 32 (1993) 178-193, http://dx.doi.org/10.1021/ie00013a024.

[34] US EPA EPISuite 4.1, US EPA, Estimation Programs Interface SuiteT ${ }^{\mathrm{TM}}$ for Microsoft ${ }^{\circledR}$ Windows, WSKowwin v 1.42, United States Environmental Protection Agency, Washington, DC, USA, 2012.

[35] M.A.R. Martins, Studies for the Development of New Separation Processes With Terpenes and Their Environmental Distribution, University of Aveiro, 2017 (PhD Thesis).

[36] K. Knobloch, A. Pauli, B. Iberl, H. Weigand, N. Weis, Antibacterial and antifungal properties of essential oil components, J. Essent. Oil Res. 1 (1989) 119-128, http:// dx.doi.org/10.2174/0929867033457719.

[37] C. Tsonopoulos, Thermodynamic analysis of the mutual solubilities of normal alkanes and water, Fluid Phase Equilib. 156 (1999) 21-33, http://dx.doi.org/10. 1016/S0378-3812(99)00021-7.

[38] A. Maczynski, B. Wisniewska-Goclowska, M. Goral, Recommended liquid-liquid equilibrium data. Part 1 . Binary alkane-water systems, J. Phys. Chem. Ref. Data 35 (2004) 549-577, http://dx.doi.org/10.1002/chin.200443265.

[39] R.R. Krug, W.G. Hunter, R.A. Grieger, Enthalpy-entropy compensation. 2. Separation of the chemical from the statistical effect, J. Phys. Chem. 80 (1976) 2341-2351, http://dx.doi.org/10.1021/j100562a007.

[40] O. Ferreira, S.P. Pinho, Solubility of flavonoids in pure solvents, Ind. Eng. Chem. Res. 51 (2012) 6586-6590, http://dx.doi.org/10.1021/ie300211e.

[41] S.J. Gill, N.F. Nichols, I. Wadsö, Calorimetric determination of enthalpies of solution of slightly soluble liquids II. Enthalpy of solution of some hydrocarbons in water and their use in establishing the temperature dependence of their solubilities, J. Chem. Thermodyn. 8 (1976) 445-452, http://dx.doi.org/10.1016/00219614(76)90065-3.

[42] G.T. Hefter, Critical evaluation of toluene + water solubility, in: A.S. Kertes, D.G. Shaw (Eds.), IUPAC Solubility Data Ser, 37, Pergamon Press, Oxford 1989, pp. 369-375.

[43] T. Gouin, D. Mackay, E. Webster, F. Wania, Screening chemicals for persistence in the environment, Environ. Sci. Technol. 34 (2000) 881-884, http://dx.doi.org/10.1021/ es991011z.

[44] V. Štejfa, F. Dergal, I. Mokbel, M. Fulem, J. Jose, K. Růžička, Vapor pressures and thermophysical properties of selected monoterpenoids, Fluid Phase Equilib. 406 (2015) 124-133, http://dx.doi.org/10.1016/j.fluid.2015.07.031.

[45] D.H. Zaitsau, S.P. Verevkin, A.Y. Sazonova, Vapor pressures and vaporization enthalpies of 5-nonanone, linalool and 6-methyl-5-hepten-2-one. Data evaluation, Fluid Phase Equilib. 386 (2015) 140-148, http://dx.doi.org/10.1016/j.fluid.2014.11.026.

[46] S.P. Verevkin, Determination of the ortho -, para -, and meta -interactions in secondary -alkylphenols from thermochemical measurements, Berichte Der Bunsengesellschaft Für Phys. Chemie. 102 (1998) 1467-1473, http://dx.doi.org/10. 1002/bbpc.199800015. 
[47] V.V. Serpinskii, S.A. Voitkevich, N.Y. Lyuboshits, Determination of saturated vapour pressures of fragrances, Zhurnal Fiz. Khimii. 27 (1953) 1032-1038.

[48] George Wypych, Knovel Solvents - A Properties Database, ChemTec Publishing, 2008/2012 (Online version. Available at) http://app.knovel.com/hotlink/toc/id: kpKSAPD005/knovel-solvents-properties/knovel-solvents-properties.

[49] M. Harini, J. Adhikari, K.Y. Rani, Prediction of vapor-liquid coexistence data for pcymene using equation of state methods and Monte Carlo simulations, J. Chem. Eng. Data 59 (2014) 2987-2994, http://dx.doi.org/10.1021/je5001022.
[50] D. Mackay, W.Y. Shiu, K.-C. Ma, S.C. Lee, Handbook of Physical-Chemical Properties and Environmental Fate for Organic Chemicals, Volume I, 2, Taylor \& Francis Group, 2006.

[51] S. Griffin, S.G. Wyllie, J. Markham, Determination of octanol-water partition coefficient for terpenoids using reversed-phase high-performance liquid chromatography, J. Chromatogr. A 864 (1999) 221-228, http://dx.doi.org/10.1016/S00219673(99)01009-2. 